\title{
Growth Regulation in Hydra: Relationship between Epithelial Cell Cycle Length and Growth Rate
}

\author{
Thomas C. G. Bosch and Charles N. David ${ }^{1}$ \\ Zoologisches Institut der Universität München, Luisenstrasse 14, Munich, West Germany \\ Received August 16, 1983; accepted in revised form March 19, 1984
}

\begin{abstract}
The relationship between epithelial cell production and growth rate was investigated in Hydra attenuata under different feeding regimes. The increase of epithelial cell number was compared to the duration of the epithelial cell cycle using standard methods of cell cycle analysis. The results indicate that cell cycle changes accompanying changes in feeding regime are not sufficient to explain the altered growth rate. Under heavy feeding regimes, epithelial cell production equals tissue growth rate. At low feeding level or under starvation conditions the epithelial cell cycle lengthens and growth rate of epithelial cell population is slowed. However, the cell cycle changes are insufficient to account for the reduction in tissue growth and thus there is an effective overproduction of epithelial cells amounting to $10 \%$ per day. Evidence suggests that these excess cells are phagocytized by neighboring cells in the tissue. Thus phagocytosis is directly or indirectly involved in regulating the growth of hydra tissue.
\end{abstract}

\section{INTRODUCTION}

It is a well-known fact in microbial as well as multicellular organisms that the amount of food ingested affects growth. In hydra growth results in the formation of new individuals through asexual budding rather than in increase in the size of the adult (Stiven, 1962). It has recently been shown that the growth rate of hydra is determined primarily by the epithelial cells (Marcum and Campbell, 1978; Sugiyama and Fujisawa, 1978; Takano et al., 1980). Hence, an understanding of the regulation of growth in Hydra requires knowledge of the relationship between epithelial cell production (i.e., the epithelial cell cycle length) and growth rate in hydra. This relationship was investigated previously by David and Campbell (1972) and Otto and Campbell (1977). In both papers it was suggested that there are cell cycle changes in response to altered feeding rates. Therefore, it was assumed that the epithelial cell cycle duration is strongly correlated with the feeding condition. However, continuous labeling experiments had shown that the epithelial cell cycle length obviously was independent of feeding levels over a wide range of different feeding rates (Fig. 3 in Otto and Campbell, 1977). Furthermore, the data of Otto and Campbell indicate that under some feeding regimes considerably more epithelial cells are produced than are utilized to form buds or are lost by tentacle tissue turnover (Fig. 11 in Otto and Campbell, 1977).

In the present paper we have reinvestigated this issue in seeking to clarify the relation between epithelial cell

\footnotetext{
${ }^{1}$ To whom correspondence should be addressed.
}

production and growth rate. In different feeding regimes the increase of epithelial cell number was compared to the duration of the epithelial cell cycle using standard methods of cell cycle analysis. The experiments were done with and without an adaptation period of 2 weeks.

The results indicate that cell cycle changes accompanying changes in feeding regime are not sufficient to explain the altered growth rate. Under heavy feeding regimes, epithelial cell production equals tissue growth rate. At low feeding level or under starvation conditions the epithelial cell cycle lengthens and hence growth rate of epithelial cell population is slowed. However, since tissue growth is proportionately more strongly reduced under these conditions, there is an effective overproduction of epithelial cells. We report here evidence suggesting that the "excess" epithelial cells are removed by phagocytosis.

\section{MATERIALS AND METHODS}

\section{Strains}

Two strains of Hydra attenuata and one strain of $H$. oligactis were used in the present study. All strains were obtained from Professor P. Tardent, Zürich. One of the $H$. attenuata strains (in the present paper called $H$. attenuata strain 1) has been cultured asexually in the laboratory since 1966; the other strain ( $H$. attenuata strain 2) was isolated from the wild in 1980 . This strain and the $H$. oligactis strain were obtained from Professor Tardent several weeks before the experiments started.

\section{Culture Conditions}

Animals were mass cultured according to Loomis and Lenhoff (1956) in a modified medium containing $1 \mathrm{~mm}$ 
$\mathrm{CaCl}_{2}, 0.1 \mathrm{~m} \mathrm{M} \mathrm{MgCl}, 0.1 \mathrm{mM} \mathrm{KCl}$, and $1 \mathrm{mM} \mathrm{NaHCO}$ in deionized water, adjusted to $\mathrm{pH} 7.8$ with $\mathrm{HCl}$. The mass culture and all the experiments were carried out in a constant-temperature room maintained at $18 \pm 1^{\circ} \mathrm{C}$. Hydra were fed freshly hatched Artemia nauplii once daily and washed 4-6 hr later. In most experiments individual animals were fed specific numbers of Artemia by hand.

\section{Standard Hydra}

To compare polyps cultured under the same conditions in the same stage of development we used "standard hydra" in all experiments. Standard hydra are defined here as small animals recently detached from parents, bearing no buds, and collected from a well-fed mass culture.

The animals selected for each experiment were maintained on the specific feeding regime for 2 days before the start of the experiment. In one set of experiments the animals were maintained on the specific feeding regime for 14 days before the start of the experiment. These latter animals are referred to as "adapted."

\section{Cell Number per Polyp}

The total number of epithelial cells per polyp was determined using the maceration technique (David, 1973; 1983). In all experiments hydra were macerated including the tentacles and buds. At each time point 5-10 animals were macerated. To improve the maceration of starved animals they were incubated for $5 \mathrm{~min}$ at $30^{\circ} \mathrm{C}$ in the maceration solution.

\section{Parameters of Growth}

Standard hydra were selected from the mass culture and placed in $5 \mathrm{~cm}$ petri dishes (10 hydra/dish). The hydra were fed once daily according to the respective feeding regime and the following two growth parameters were determined.

Growth of epithelial cell population. The growth rate $(k)$ of an exponentially growing culture is defined as

$$
n / n_{0}=e^{k t}
$$

where $n$ is the total number of epithelial cells at time $t$ and $n_{0}$ the number of cells at $t_{0}$. For $n / n_{0}=2, t=T_{\mathrm{D}}$, the doubling time of the cell population. $T_{\mathrm{D}}$ was determined by linear regression.

Budding rate. Budding rate was determined as the average number of buds produced per hydra per day. Experimentally the increase of buds per hydra was counted daily.

\section{Determination of the Cell Cycle Length}

The length of the epithelial cell cycle was determined by the continuous labeling with $\left[{ }^{3} \mathrm{H}\right]$ thymidine (Campbell and David, 1972). Methyl[ $\left.{ }^{3} \mathrm{H}\right]$ thymidine (Amersham Buchler, Braunschweig; specific activity $44 \mathrm{Ci} / \mathrm{ml}$ ) was injected into the gastric cavity at a concentration of 100 $\mu \mathrm{Ci} / \mathrm{ml}$ (about $0.5 \mu \mathrm{l} /$ injection). Under these conditions essentially all injected isotope is incorporated within 30 to $60 \mathrm{~min}$. There is no detectable effect of food in the gastric cavity on the extent of incorporation (David and Challoner, unpublished observations). Continuous labeling was achieved by repeated injections at $12-\mathrm{hr}$ intervals. In all experiments 5-10 animals (including tentacles and buds) were macerated. The slides were dipped in autoradiographic emulsion (Kodak NTB 2), exposed for 5-8 days at $4^{\circ} \mathrm{C}$, and developed. Labeled epithelial cells have 50 to 100 silver grains per nucleus under these conditions. The labeling index (labeled nuclei/total number of nuclei) was determined by examining 300500 epithelial cells per sample.

The cell cycle length was determined by fitting the labeling index (LI) curves (Figs. 1B and $4 B$ ) to a theo-

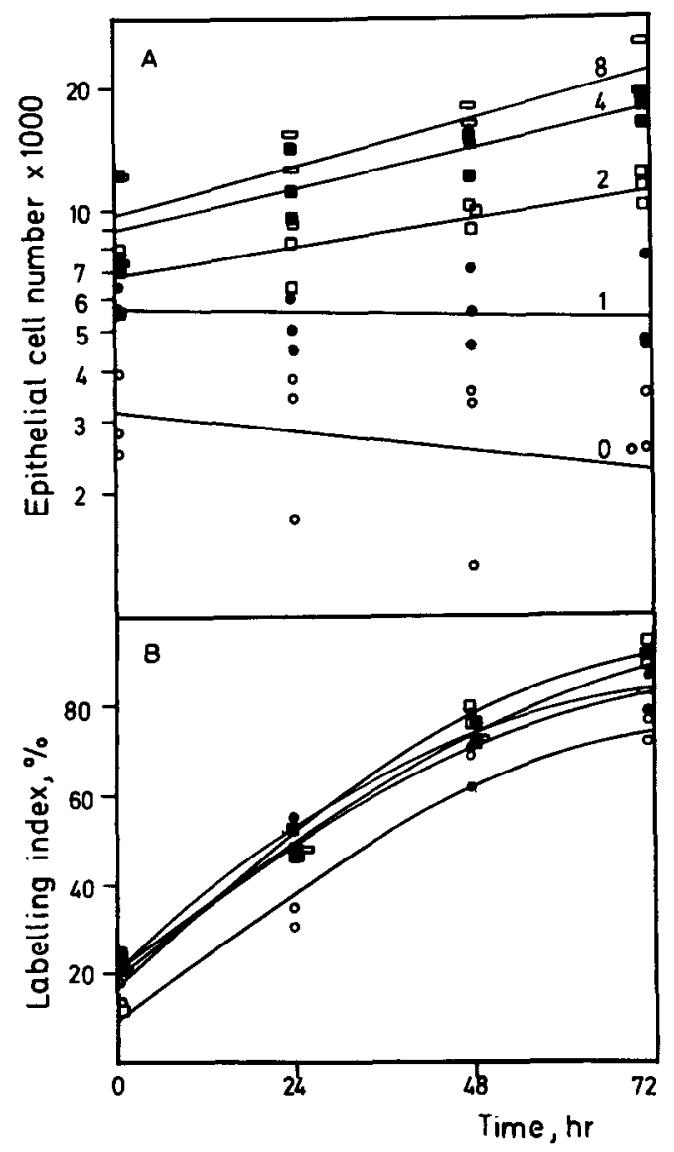

FIG. 1. Increase of epithelial cell number (A) and labeling index (B) for different feeding regimens. $\square, 8$ shrimp/hydra/day. $\square, 4$ shrimp/ hydra/day. $\square, 2$ shrimp/hydra/day. $\bullet, 1$ shrimp/hydra/day. 0,0 shrimp/hydra/day. Hydra were selected from mass culture 2 days before start of the experiments and fed once daily according to the feeding regime. Data are presented from three independent experiments. Lines in (A) are least-squares regression lines. 
retical curve for an exponentially growing population having S phase of $12 \mathrm{hr}$ (David and Campbell, 1972) and an unknown cell cycle duration $(T)$. Since $\mathrm{G1}=0$ in hydra cells, the $S$ phase occurs at the beginning of the cell cycle. For such an exponentially growing population the age distribution of cells over the cycle is given by

$$
y=2^{(1-t / T)}
$$

where $y$ is the relative number of cells at time $t$ in the cell cycle of length $T$.

Integration of this function yields an expression for the relative number of cells $(A)$ in a particular cell cycle interval between 0 and $t / T$

$$
A=(2 / \ln 2)\left(1-2^{-t / T}\right) .
$$

The total number of cells in the population, obtained by evaluating the integral for $t=T$, is $1 / \ln 2$. Hence the labeling index (LI) is

$$
\mathrm{LI}=2\left(1-2^{-t / T}\right) \text {. }
$$

Rearranging this expression and taking the logarithm, we obtain

$$
\ln (1-\mathrm{LI} / 2)=(-\ln 2 / T)(t) .
$$

Plotting the experimental data in this form yields a straight line with slope $-\ln 2 / T$. The cell cycle duration $T$ could then be determined by linear regression.

\section{Histological Methods}

For identification of mitotic epithelial cells maceration preparations were stained by the Feulgen method (Romeis, 1968). Feulgen staining was also used to identify and count phagocytic vacuoles.

For further characterization of the phagocytic vacuoles maceration preparations were stained with the fluorochrome Hoechst-33258 (Serva, Heidelberg). Fixed maceration preparations were washed $10 \mathrm{~min}$ in water. After a drop of Hoechst-33258 $(0.5 \mu \mathrm{g} / \mathrm{ml})$ was placed on the slide it was viewed by epi-illumination using Leitz filter block A. Fluorescence photography was performed with Kodak recording film 2475 exposed for 0.55 min.

\section{Morphometric Anaylsis of Epithelial Cells}

The size of epithelial cells (ectodermal and endodermal) was estimated by determining the area of the flattened cell in maceration preparations. Measurements of the area were made hy tracing the profile of a cell using a camera lucida and then using a digitizer (Summagraphics) coupled to a minicomputer (Kontron PSI $80)$ to determine the area of the profile. For each analysis 50-100 epithelial cells were examined. Repeated measurements of the area of a single cell gave a series of values having a standard deviation of about $0.25 \%$ of the surface area of the cell.

Two control experiments support the validity of this morphometric procedure: (1) Cells in $S$ phase (i.e., $\left[{ }^{3} \mathrm{H}\right]$ thymidine labeled) at the beginning of the cell cycle have an average area of $650 \pm 220 \mu \mathrm{m}^{2}$ compared to cells in G2 which have an average area of $920 \pm 260 \mu \mathrm{m}^{2}$. (2) Cells in metaphase have an area of $530 \pm 130 \mu \mathrm{m}^{2} \mathrm{com}-$ pared to daughter cells in telophase which have an area of $320 \pm 135 \mu \mathrm{m}^{2}$. The difference in area between mitotic and interphase cells presumably indicates a difference in the cytoskeletal structure of these cells.

\section{RESULTS}

\section{Effect of Feeding on the Increase of Epithelial Cell Number and on Bud Formation}

To determine the increase of the epithelial cell number standard $H$. attenuata strain 1 were taken from the culture and fed 0, 1, 2, 4, or 8 shrimp per day. Experiments were started after a 2-day adaptation period to the controlled feeding conditions. The results of three independent experiments are shown in Figs. $1 \mathrm{~A}$ and 2. The increase in epithelial cell number and budding rate is directly related to the feeding rate. Starved animals ( 0 or 1 shrimp/hydra/day) do not grow, while feeding more shrimp causes a progressive increase in epithelial cell number and budding rate. The results are consistent with previous findings (Loomis, 1954; Schroeder, 1969; Bode et al., 1973; Otto and Campbell, 1977) and are used to calculate the doubling time $T_{\mathrm{D}}$ of the epithelial cell population (Table 1).

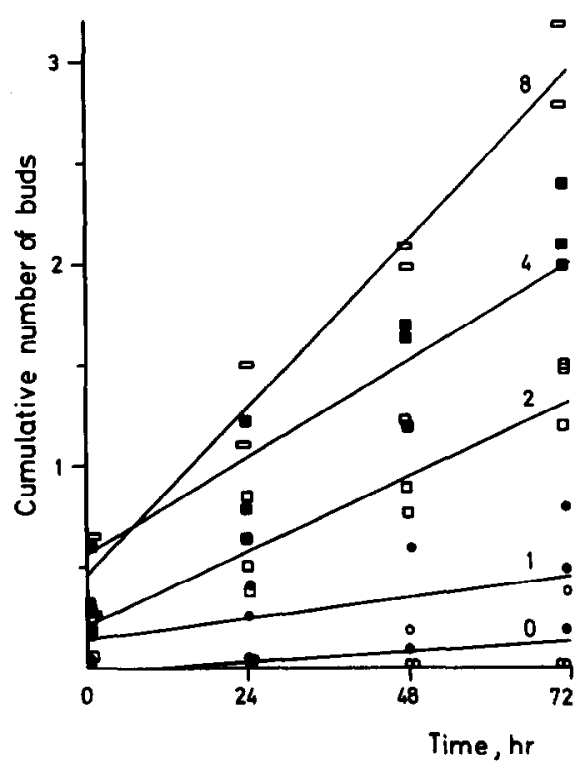

FIG. 2. Cumulative bud formation under different feeding regimes. Data are presented from three independent experiments. Symbols are same as in Fig. 1. Lines are least-squares regression lines. 
TABLE 1

Relationship between Doubling Time of Epithelial Cell Population and Epithelial Ceill Cycle length

\begin{tabular}{lcccc}
\hline & $\begin{array}{c}\text { Feeding rate } \\
\text { (Artemia) } \\
\text { hydra/day) }\end{array}$ & $\begin{array}{c}\text { Doubling } \\
\text { time of } \\
\text { epithelial cell } \\
\text { population }\end{array}$ & $\begin{array}{c}\text { Epithelial } \\
\text { cell cycle } \\
\text { length }^{b}\end{array}$ \\
\hline H. attenuata strain 1 & 0 & $-4.2 \pm 7.4$ & $5.0 \pm 0.9$ \\
(without adaptation & 1 & $50.2 \pm 384$ & $5.0 \pm 0.8$ \\
period) & 2 & $4.2 \pm 1.8$ & $4.0 \pm 0.6$ \\
& 4 & $3.1 \pm 1.4$ & $4.1 \pm 0.5$ \\
(after adaptation & 8 & $2.5 \pm 1.2$ & $4.6 \pm 2.2$ \\
period of 2 weeks) & 0 & $-12.8 \pm 46$ & $7.2 \pm 1.5$ \\
& 1 & $18.8 \pm 91$ & $4.5 \pm 1.5$ \\
& 2 & $8.6 \pm 14$ & $5.1 \pm 2.4$ \\
H. oligactis & 4 & $2.7 \pm 0.9$ & $5.0 \pm 1.5$ \\
(without adaptation & 8 & $2.7 \pm 1.2$ & $4.6 \pm 2.3$ \\
period) & 1 & 13.8 & 3.9 \\
H. attenuata strain 2 & 4 & 2.1 & 3.8 \\
(without adaptation & 4 & & & \\
period) & 4 & 3.8 & $6.9^{\circ}$ \\
\hline
\end{tabular}

a Calculated from results in Figs. 1A and 4A using linear regression. The error indicates the $95 \%$ confidence interval. Negative values are due to decrease of total cell number.

${ }^{b}$ Calculated from the results in Figs. $1 \mathrm{~B}$ and $4 \mathrm{~B}$ using linear regression procedure described under Materials and Methods. The error indicates the $95 \%$ confidence interval.

' The comparatively long cell cycle estimates are due to aberrantly low labeling at $t_{0}$ probably as a result of an experimental error.

\section{Effect of Feeding on the Epithelial Cell Cycle Length}

The above animals were also used for cell cycle analysis. The cell cycle length of epithelial cells was determined by continuous labeling with $\left[{ }^{3} \mathrm{H}\right]$ thymidine. The cell cycle length was calculated from the labeling curve (Fig. 1B) using the procedure described under Materials and Methods. Figure 1B shows the combined results of two independent labeling experiments carried out with $H$. attemuata strain 1 . The results indicate that most epithelial cells (70-90\%) pass through $S$ phase at least once in 3 days. Even in starved animals (0 shrimp/ hydra/day) about $75 \%$ of the epithelial cells are labeled after 3 days although in these animals no increase of the epithelial cell number can be observed (Fig. 1A). The calculated epithelial cell cycle lengths (Table 1) indicate that reduction of the feeding level from 8 shrimp per day to 0 shrimp per day is accompanied by about a 1.5-fold lengthening of the epithelial cell cycle.

Figure 3 summarizes the results and shows the relationship between the length of the epithelial cell cycle and the doubling time of the epithelial cell population. In all feeding classes (0-8 shrimps/hydra/day) the epithelial cell cycle had a duration of 4 to 5 days whereas the doubling time of the epithelial cells was strongly dependent on the feeding rate. Under unfavorable feeding conditions (0-2 shrimp/hydra/day) the epithelial cell cycle was significantly shorter than the doubling time of the epithelial cell population.

The same experiments were also carried out with $H$. attenuata strain 2 and $H$. oligactis. With both strains qualitatively similar results were obtained (Table 1) indicating that the discrepancy between cell cycle duration and population growth rate is not a unique feature of our particular laboratory strain of hydra.

\section{Significance of an Adaptation Period}

To exclude the possibility that our results were influenced by the transition from the mass culture to defined feeding regimes we repeated all the experiments after an adaptation period of 2 weeks. Figure 4 shows the results of two independent experiments carried out after hydra were preadapted for 2 weeks to each feeding regime. The increase of epithelial cell number and the labeling curve were very similar to the results without the adaptation period (Figs. 1 and 4). In particular the results indicate that there is no increase in the epithelial cell population in animals fed 1 shrimp per day, despite the fact that $70 \%$ of the epithelial cells have passed through the $S$ period in 3 days. Hydra fed 0 shrimp for 2 weeks decreased in size, but $50-60 \%$ of their epithelial cells were still labeled in 3 days. Table 1 indicates that the cell cycle lengths varied from about 4 days in fed animals to about 7 days in starving animals. The similarity of the results with and without an adaptation period suggests that in both cases hydra were sufficiently equilibrated to the new feeding regime.

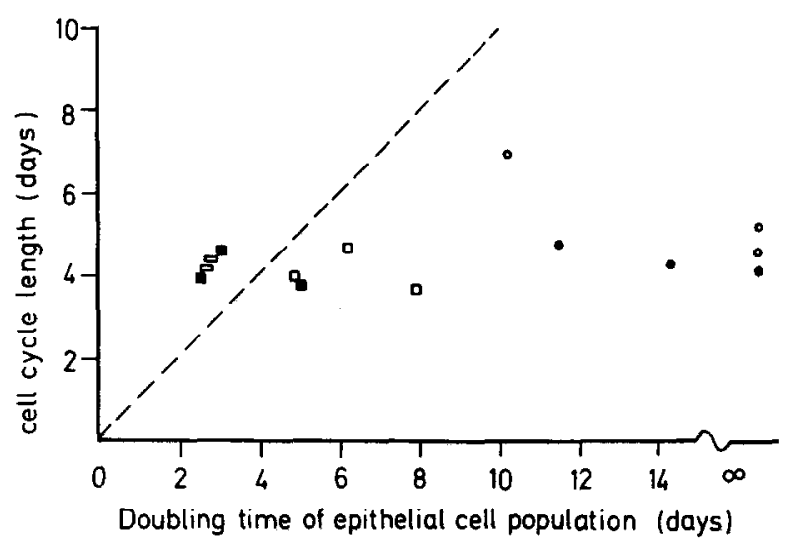

FIG. 3. Relationship between doubling time of the epithelial cell population (abscissa) and cell cycle length (ordinate) under different feeding regimes. Data were taken from Fig. $1 \mathrm{~A}$ and B. $\square, 8$ shrimp/ hydra/day. ఐ, 4 shrimp/hydra/day. $\square, 2$ shrimp/hydra/day. $\bullet, 1$ shrimp/hydra/day. O, 0 shrimp/hydra/day. The dashed line shows the theoretical line when the epithelial cell cycle. length is exactly equal to the doubling time of the epithelial cell population. 


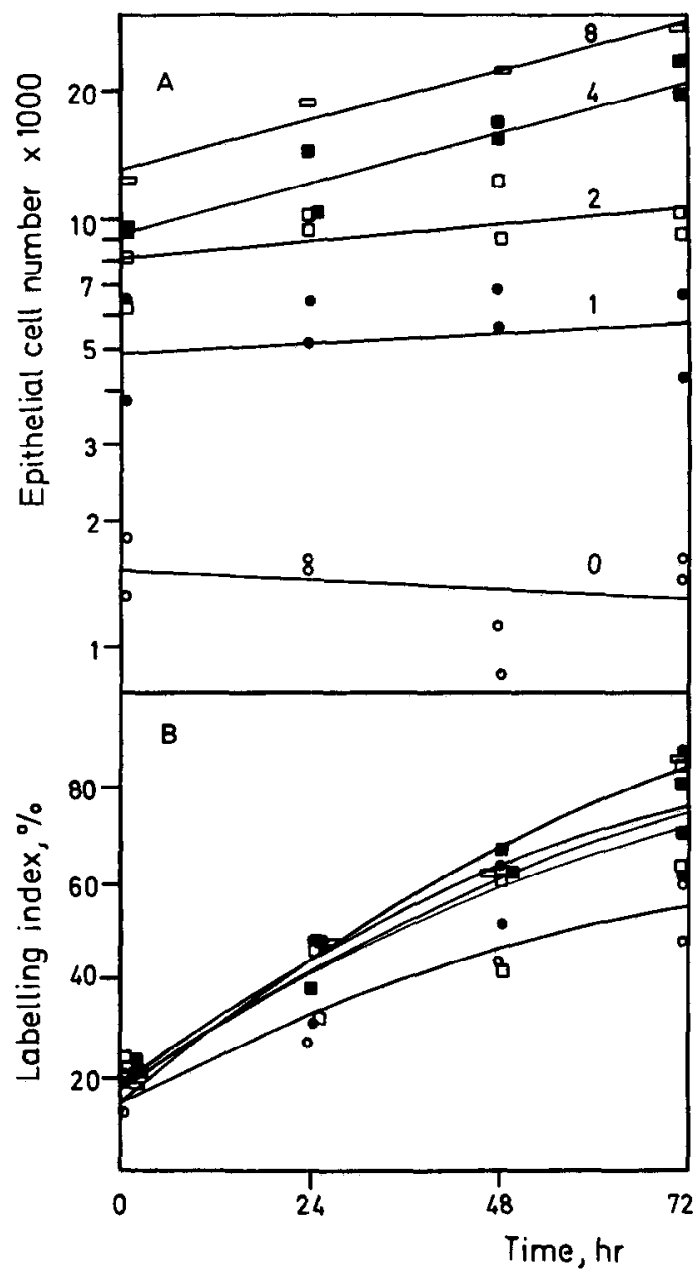

FIG. 4. Increase of epithelial cell number (A) and labeling index (B) for different feeding regimes after an adaptation period of 2 weeks. $\square, 8$ shrimp/hydra/day. $\square, 4$ shrimp/hydra/day. a, 2 shrimp/hydra/ day. 1 shrimp/hydra/day. O, 0 shrimp/hydra/day. Data are shown from two independent experiments. Lines in $\mathrm{A}$ are least-squares regression lines.

\section{Estimation of Fraction of Dividing Epithelial Cells from Mitotic Index}

To estimate directly the fraction of epithelial cells dividing each day in different feeding regimes, we determined the mitotic index over a 24 -hr period. Hydra were fed $0,1,2$, or 4 shrimp right before the start of the experiment. At regularly timed intervals three animals were sampled by maceration and the percentage of mitotic epithelial cells (i.e., metaphases, anaphases, and telophases) was determined.

Figure 5 shows the variation of the mitotic index over a 24-hr period for each feeding class. In agreement with previous observations (David and Campbell, 1972) there is distinct increase in mitotic cells 8-12 hr after feeding due to partial synchronization of the epithelial cell population. The size of the mitotic peak increases with in- creasing feeding level: heavy feeding ( 4 shrimp/hydra) induces more epithelial cell mitosis than light feeding. In the absence of food no mitotic peak can be observed. However, such animals do exhibit a basal level of about $0.8 \%$ mitotic epithelial cells continuously throughout the 24 -hr period. This basal level of mitoses is also present in fed animals.

The results in Fig. 5 indicate a difference in the level of mitotic epithelial cells in different feeding regimes. We have quantitated this difference by integrating the area under the curves in Fig. 5. Assuming an average mitosis length of $1.5 \mathrm{hr}$ (David and Campbell, 1972) the results (Table 2) indicate that approximately $10 \%$ of epithelial cells per day divide in unfed animals compared to $20-25 \%$ in fed animals. Thus, these results also provide clear evidence for extensive epithelial cell proliferation in animals fed 0 or 1 shrimp per day in which the epithelial cell population does not increase in size.

\section{Comparison of Epithelial Cell Size under Different Feeding Regimes}

Cell size can be modulated by nutrient conditions. In bacteria (Donachie et al., 1973) and in yeast (Fantes and Nurse, 1977) cell size diminishes under limiting nutrient conditions. To investigate whether cell size in hydra is related to the respective feeding regime we developed a morphometric technique to estimate the size of epithelial cells by measuring the area they occupy in maceration preparations (see Materials and Methods).

Table 3 shows measurements of the size of interphase

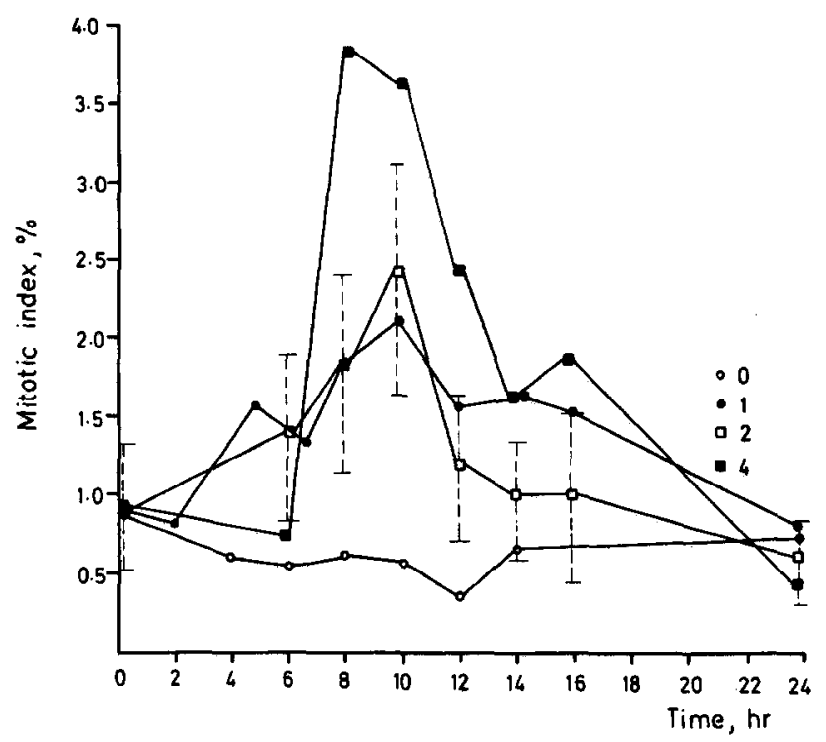

Fig. 5. Temporal variation in the mitotic index of epithelial cells under different feeding regimes. Hydra were selected from mass culture 2 days before start of the experiments and fed once daily according to the feeding regime. Three hydra per feeding regime were macerated at each time point. Hydra were fed for the last time immediately before start of the experiment. Bars represent $95 \%$ confidence interval. 
TABLE 2

Doubling Time of Epithelial Cell Population Calculated FROM MITOTIC INDEX

\begin{tabular}{ccc}
\hline & $\begin{array}{c}\text { Fraction of } \\
\text { epithelial cells } \\
\text { dividing per } \\
\text { day }^{a}\end{array}$ & $\begin{array}{c}\text { Calculated doubling } \\
\text { time (days) }\end{array}$ \\
\hline 0 & 0.10 & 6.9 \\
1 & 0.22 & 3.1 \\
2 & 0.19 & 3.6 \\
4 & 0.26 & 2.7 \\
\hline
\end{tabular}

\footnotetext{
${ }^{a}$ Obtained by integration of the area under the curve in Fig. 5 and assuming mitosis lasts $1.5 \mathrm{hr}$.

${ }^{b} T_{\mathrm{D}}=\ln 2(1 / k)$ where $k=$ fraction of epithelial cells dividing per day.
}

and mitotic epithelial cells from animals in different feeding classes. Representative distributions of interphase epithelial cells from animals fed 0 and 4 Artemia/ hydra/day are shown in Fig. 6. The results indicate that the size of epithelial cells in both interphase and mitosis is similar in all tested feeding regimes. Thus, in $H y d r a$ there appears to be no correlation between feeding level and epithelial cell size: even under starvation epithelial cells appear to grow and maintain their specific mean size.

\section{Observation of Phagocytic Vacuoles in Epithelial Cells}

While scanning cell macerations for epithelial mitotic figures we observed occasional epithelial cells which appeared to contain cells or cell fragments in vacuoles. Using the Feulgen method with light green counterstain it was possible to distinguish cytoplasm (green) and chromatin (red) in such vacuoles. Figure 7 shows some of these epithelial cells. The micrographs show epithelial cells which appear to be in the process of engulfing other cells and forming a vacuole (Figs. $7 \mathrm{a}$ and $\mathrm{b}$ ). In other cells the pycnotic condensation of chromatin results in a reduced nuclear volume and the nucleus appears to distintegrate into several, intensively Feulgen-positive chromatin granules (Figs. 7c, e, and f). Furthermore, there are cells in which staining with the Schiff's reagent

TABLE 3

Size of Epithelial Cells under Various Feeding Rates

\begin{tabular}{lcccc}
\hline & \multicolumn{4}{c}{ Feeding rate (shrimp/day) } \\
\cline { 2 - 5 } $\begin{array}{l}\text { Epithelial } \\
\text { cells }\end{array}$ & 0 & 1 & 2 & 4 \\
\hline Interphase & $892 \pm 312$ & $917 \pm 311$ & $813 \pm 218$ & $786 \pm 266$ \\
Mitosis & $583 \pm 214$ & $531 \pm 236$ & $501 \pm 175$ & $537 \pm 236$ \\
\hline
\end{tabular}

Note. Values given are means $\pm \mathrm{SD}$ in $\mu \mathrm{m}^{2}$.

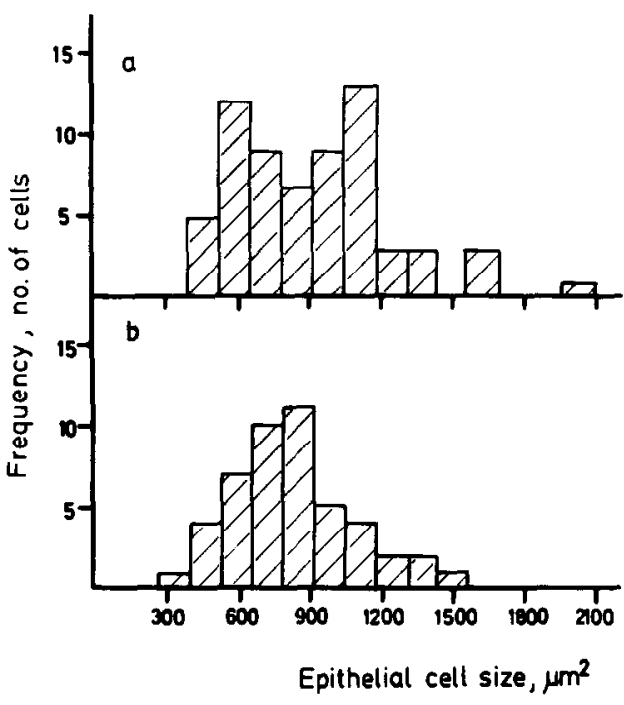

FIG. 6. Distribution of epithelial cell size in animals fed 0 shrimp/ hydra/day (a) and 4 shrimp/hydra/day (b).

is decreased and the nucleus of the enclosed cell disappears. Such morphological stages are characteristic of the multiphased process of phagocytosis (Walters and Papadimitriou, 1978) and, therefore, we interpret such vacuoles containing cells or cell fragments as phagocytic vacuoles. The sequence of photographs in Fig. 7 suggests the sequence of events in the phagocytic process.

Phagocytic vacuoles containing whole cells or cell fragments can also be observed in maceration preparations which are stained with the DNA-specific fluorochrome Hoechst-33258. The fluorochrome stains the nucleus of the epithelial cell as well as the chromatin of the engulfed cell. In Fig. 8 only part of the vacuole is stained suggesting that there is a cytoplasmic portion beyond the chromatin.

To exclude the possibility that these vacuoles represent stored food vacuoles we examined macerations of isolated ectodermal cells. The occurrence of phagocytic vacuoles in such ectodermal epithelial cells indicates that the vacuoles do not represent food vacuoles since these are found only in endodermal cells (Gauthier, 1963). In addition we have observed such vacuoles in animals which had not been fed for 20 days.

\section{Increase of Phagocytic Vacuoles under Starvation}

To estimate the extent of cellular phagocytosis the number of epithelial cells containing phagocytic vacuoles was determined. Standard animals were selected from the mass culture and fed $0,1,2$, or 4 shrimps once daily. After 2 days of adaptation to the feeding regime several hydra per feeding regime were macerated and stained by the Feulgen method, and the percentage of epithelial 

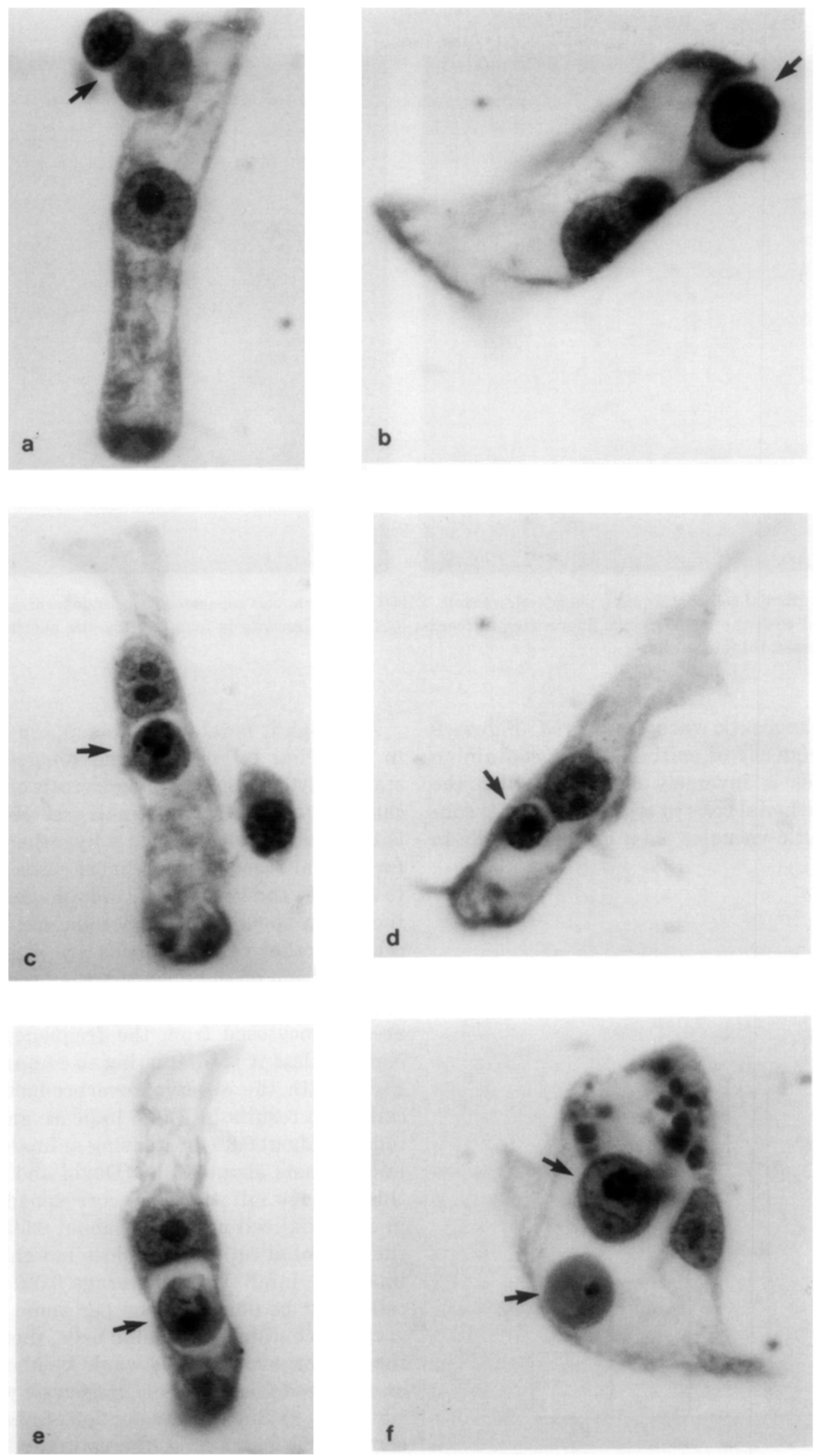

FIG. 7. Epithelial cells containing phagocytic vacuoles. The cells are stained by the Feulgen method using light green counterstain. $\times 1130$. Epithelial cells engulf other cells ( $a$ and $b$ ). The cytoplasm (gray) and the chromatin (dark spots) of the engulfed cell is condensed. The nucleus disintegrates into several chromatin granules (c-e). At later stages the affinity of the nucleus to the Schiff's reagent decreases. Finally the nucleus of the phagocytosed cell disappears (f). Arrows indicate phagocytosed cells. 

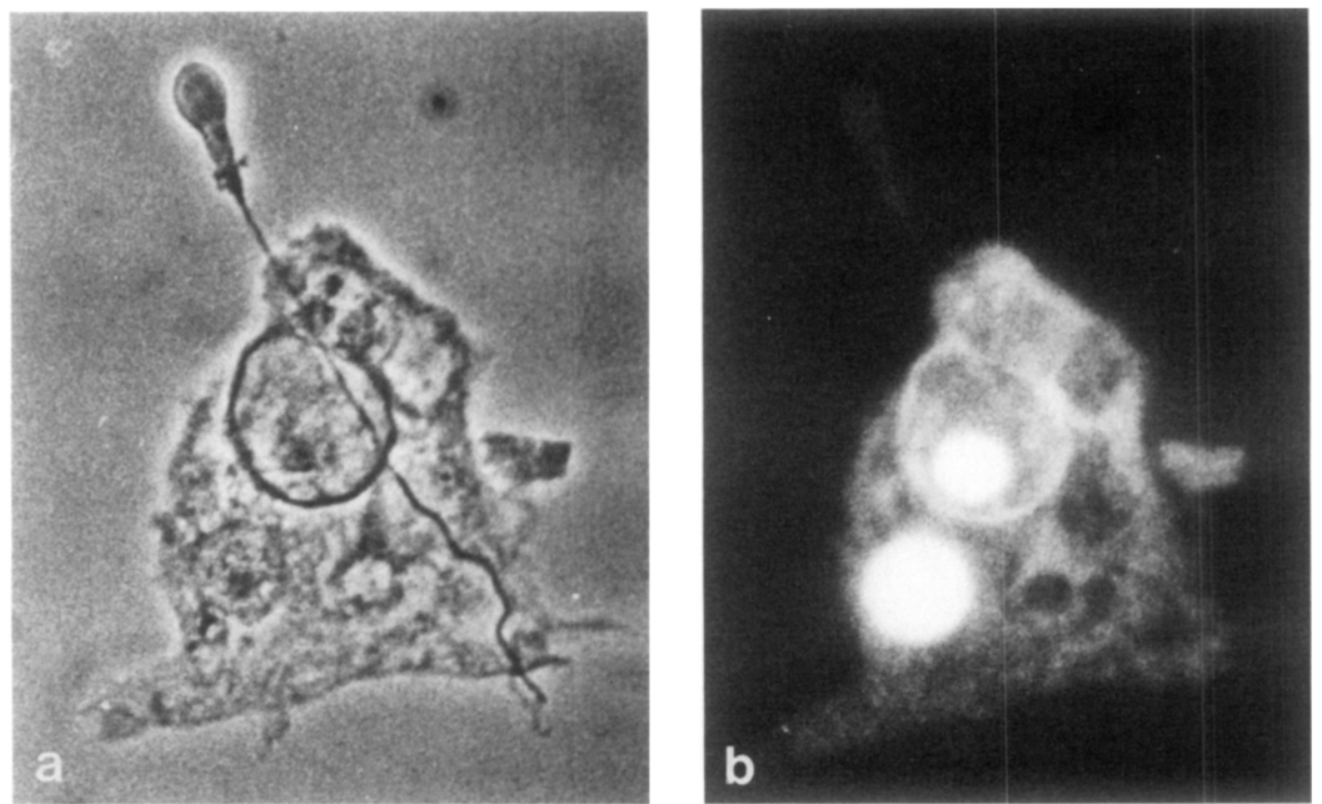

FIG. 8. Ectodermal epithelial cell containing a phagocytic vacuole. $\times 1250$. Ectoderm was separated from endoderm during maceration and the preparation stained with the DNA specific fluorochrome Hoechst-33258. Fluorescence is found within the nucleus and in part of the vacuole. (a) Phase-contrast; (b) fluorescence.

cells containing phagocytic vacuoles scored. Figure 9 shows that the frequency of epithelial cells containing phagocytic vacuoles is inversely correlated with the feeding regime: epithelial cells in starving animals contain more phagocytic vacuoles than epithelial cells in well-fed animals.

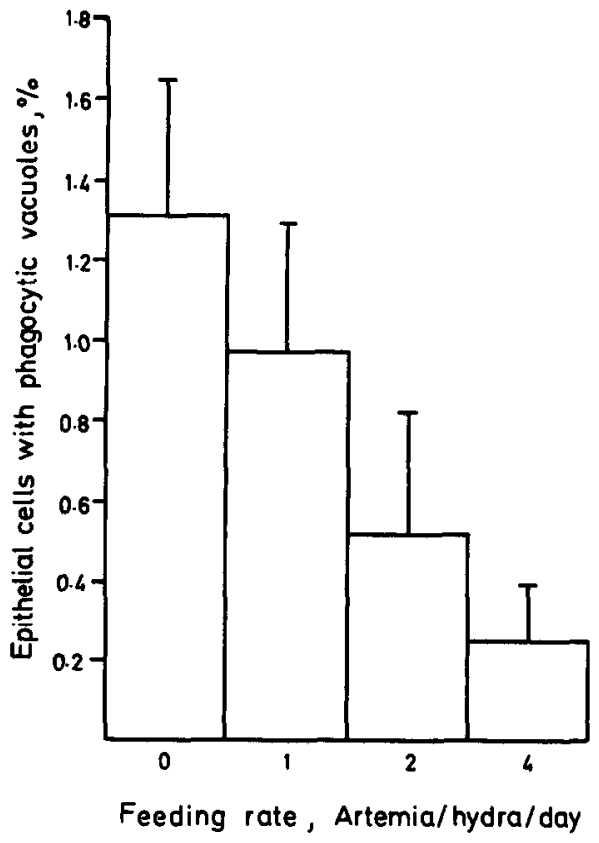

FIG. 9. Frequency of epithelial cells containing phagocytic vacuoles under different feeding regimes. Values represent means \pm SD.
Although it is tempting to suppose that the increase in epithelial cells containing phagocytic vacuoles in starved hydra is due to phagocytosis of excess epithelial cells produced in such animals (see above), presently it is not possible to test such a hypothesis quantitatively for several reasons. (1) In most cases it is not possible to identify the type of cell in a phagocytic vacuole. Although in some cases such cells are clearly epithelial cells, in other cases the cells are interstitial cells. (2) The duration of the phagocytosis process is not known and therefore we cannot calculate the rate at which cells are phagocytosed from the frequency data in Fig. 9. Nevertheless it is interesting to compare the results in Fig. 9 with the observed overproduction of epithelial cells. The results in Fig. 5 indicate an average mitotic index of about $0.8 \%$ in starving animals. Assuming that mitosis lasts about $1.5 \mathrm{hr}$ (David and Campbell, 1972), this average mitotic index corresponds to an increase in epithelial cell number of about $0.5 \%$ per hour. Since the epithelial cell number does not change in such animals, we infer that on average $0.5 \%$ of the epithelial cells must be phagocytosed per hour. If all phagocytic vacuoles contained epithelial cells, then the duration of the phagocytosis process would be about $3 \mathrm{hr}$ based on an observed frequency of phagocytic vacuoles of about $1.5 \%$ (Fig. 9). Since only a portion of phagocytic vacuoles contain epithelial cells, the estimated duration of the phagocytosis process must be reduced to perhaps only 1-2 hr. This estimate of 1-2 hr does not seem unreasonable since only phagocytic vacuoles containing clearly 
recognizable cells (i.e., the earliest phases of the phagocytosis process) were scored in Fig. 9. Thus it appears possible that cellular phagocytosis plays a significant role in the removal of "overproduced" epithelial cells in hydra.

\section{DISCUSSION}

\section{Effect of Feeding on Cell Cycle Length}

Cell cycle lengths of hydra epithelial cells were determined under different feeding regimes by continuous labeling of these cells with $\left[{ }^{3} \mathrm{H}\right]$ thymidine. Over a wide range of feeding regimes the results indicate that the epithelial cell cycle length varies only slightly (from 4 to 7 days) (Table 1). This conclusion is further supported by measurements of the mitotic activity of epithelial cells (Fig. 5 and Table 2). These results indicate the existence of a constant basal level of about $10 \%$ mitotic epithelial cells per day in both well-fed and starving animals. In addition to this basal level feeding induces division in a further $10-15 \%$ of epithelial cells per day. Assuming all cells are mitotically active, these mitotic rates yield estimates of the epithelial cell cycle of about 7 days in unfed animals and about 3-4 days in fed animals (Table 2).

There is fairly good agreement between cell cycle estimates based on $\left[{ }^{3} \mathrm{H}\right]$ thymidine labeling and estimates based on mitotic index despite the large errors in both procedures (Fig. 5 and Table 1). Nevertheless the $\left[{ }^{3} \mathrm{H}\right]$ thymidine estimates appear to be systematically longer (compare Tables 1 and 2). Although we cannot fully explain this difference it may be partly due to the presence of small numbers of slowly cycling cells which depress the labeling index at later times in Figs. 1B and 4B. If these values are excluded from the calculations in Table 1, the cell cycle estimates are generally shortened by 0.5-1 day and thus in better agreement with both the mitotic data and the growth rate.

Because Otto and Campbell (1977) observed irregularities in cell number and budding rates during the first 2 weeks after changes to new feeding regimes, we repeated all our experiments after an adaptation period of 2 weeks. Figure 4 indicates that the growth and labeling of the epithelial cell population obtained after an adaptation period of 2 weeks is very similar to the results without the adaptation period (Fig. 1). In particular we observed no growth of the epithelial cell population in animals which were fed 0 or 1 shrimp per day (Fig. 4), although $70 \%$ of the epithelial cells in these animals were labeled after 3 days. The similarity of the results with and without an adaptation period indicates that in both cases hydra are sufficiently equilibrated to the new feeding regime.
The observations above as well as similar observations of Otto and Campbell (1977) using $\left[{ }^{3} \mathrm{H}\right]$ thymidine indicate that the cell cycle is largely independent of feeding level. This is surprising for several reasons: (1) Feeding induces epithelial cell mitosis (Fig. 5 and David and Campbell, 1972). (2) Earlier work has shown that the epithelial cell cycle is quite variable in length (due to variation in G2) suggesting that its length is somehow regulated. These observations lead one to expect that growth of epithelial cell population in hydra would be regulated. The limited extent of this regulation may be due to the absence of a G1 phase in hydra epithelial cells. Since G1 is the principal site of cell cycle regulation in higher organisms, its absence in hydra could be responsible for the limited regulatory ability of these cells. In this sense hydra cells appear to have an "archetypal" cell cycle similar to many simple eucaryotes and early embryonic cells (Prescott, 1981).

\section{Production of "Excess" Epithelial Cells}

In contrast to the relative insensitivity of cell cycle length to changes in feeding regimes (see above), growth of the epithelial cell population is strongly dependent on the feeding regime (Figs. 1A and 4). Under conditions of heavy feeding growth of the epithelial cell population is rapid whereas under conditions of light feeding or starvation $(2,1$, or 0 shrimp/hydra/day) the epithelial cell population grows only slowly or not at all (Fig. 3). This difference in the response of the epithelial cell cycle and epithelial population growth to changes in feeding level has a striking effect. While the epithelial cell cycle length is approximately the same as the doubling time of the epithelial population in well fed hydra (Table 1), in lightly fed animals the cell cycle is significantly shorter than the doubling time of the epithelial cell population. Under these conditions excess epithelial cells are produced which do not appear in the epithelial cell population. The extent of this excess epithelial cell production can be quite large: for example in hydra fed 1 shrimp per hydra per day, the epithelial cell population does not change in size. Nevertheless, about $20 \%$ of the epithelial cells divide per day (Table 2) which leads to production of an "excess" of epithelial cells amounting to $20 \%$ of the epithelial cell population per day. As discussed below these cells appear to be removed from the tissue by phagocytosis.

The continued proliferation of epithelial cells and thus production of excess cells under conditions of limited feeding initially surprised us. We have, however, confirmed the essential observations on a second strain of $H$. attenuata as well as another species $H$. oligactis. Furthermore, independent observations of Otto and Campbell also indicated extensive overproduction of epithelial 
cells under conditions of limited feeding (Fig. 11, Otto and Campbell, 1977).

Similar observations have also been made by Sugiyama and Takano with $H$. magnipapillata strain L4 (Takano et al, 1980; Takano and Sugiyama, 1983; Takano, 1983; Sugiyama, personal communication). Under certain feeding conditions the epithelial cell cycle in this strain was significantly shorter than the doubling time of the animals. Further examination indicated that strain L4 has a defect in the budding mechanism: adult animals are slow to initiate buds. Under these conditions the animals no longer increase in size (epithelial cell number) although epithelial cells continue to divide. Thus it appears that the independence of tissue growth and epithelial cell cycle is a general phenomenon in hydra biology.

\section{Cellular Growth in Absence of Food}

There is ample evidence that cell size in bacteria (Donachie et $a l, 1973$ ) and yeast (Fantes and Nurse, 1977) decreases when the growth rate slows in poor medium. Since epithelial cell proliferation occurs in lightly fed hydra, it appeared possible that cell size might diminish in such animals. Thus we measured the size of epithelial cells under different feeding regimes using morphometric techniques. The results indicate that epithelial cell size in hydra is not modulated by nutrient conditions (Table 3). In particular epithelial cells in unfed animals exhibited the same distribution of cell sizes as cells in well fed animals. This simple observation suggests that normal cell growth continues to occur as cells progress through the cell cycle although no exogenous source of nutrients is available. Although this may be due in part to stored reserves, it seems likely that phagocytosis of neighboring cells and reutilization of their constituents contributes significantly to cellular growth. The results are also consistent with the idea that cell division is regulated by cell size as in many other systems; i.e., cells must grow to a certain critical size before cell division occurs (Mitchison, 1977).

\section{Phagocytosis of Cells in Hydra}

The results of the present paper indicate that significant numbers of epithelial and interstitial cells are phagocytized in animals fed low levels of shrimp. Thus phagocytosis is directly or indirectly involved in regulating the growth of hydra tissue. Although this is the first time phagocytosis has been associated with growth regulation in hydra, there are several other examples of phagocytosis in Hydra. (1) During oogenesis one cell of each group of oogonia II develops into an oocyte, which engulfs the neighboring oogonia II by phagocy- tosis (Zihler, 1972). The phagocytized cells persist as "shrunken cells" in the ooplasm and appear to be used for nutrition of the newly hatched hydra. (2) Phagocytosis also plays a role in the removal of presumable dying interstitial cells following treatment of hydra with cholchicine (Campbell, 1976). In such animals interstitial cells are eliminated through phagocytosis by both ectodermal and endodermal epithelial cells. (3) Fujisawa and David (1983) observed elimination of committed nematocyte precursors by phagocytosis when head and/ or foot tissue were removed from hydra. The authors suggested that, in regenerating tissue, cells which are not immediately required for regeneration are selectively removed by this mechanism.

Our results suggest that cellular phagocytosis may be a survival mechanism which gives hydra the possibility to sustain itself temporarily at the expense of some of its own cells.

The observation that under starvation conditions growth in cell size during the cell cycle (Table 3) is normal strongly supports the idea that phagocytized cells are reutilized for the growth of surviving cells. We also have evidence that under these conditions $\left[{ }^{3} \mathrm{H}\right]$ thymidine incorporated in the nuclei of phagocytized cells is reincorporated in surviving cells. How particular cells are selected for phagocytosis is at present unknown. Indeed we do not know whether the phagocytosis process itself is the regulator of cell proliferation or if it is only a secondary process which removes cells inactivated by the primary growth regulatory process.

We thank Dr. H. K. MacWilliams and Dr. C. J. Weijer for helpful discussions. This research was supported by a grant from the German Science Foundation (DFG Grant Da 163/1-1).

\section{REFERENCES}

Bode, H., Berking, S., David, C. N., Gierer, A., Schaller H., and TRENKNER, E. (1973). Morphogenesis in hydra. Wilhelm Roux's Arch. Entwicklungsmech. Org. 171, 269-285.

CAMPBELL, R. D. (1976). Elimination of $H y d r a$ interstitial and nerve cells by means of colchicine. J. Cell Sci 21, 1-13.

DAvID, C. N. (1973). A quantitative method for maceration of hydra tissue. Wilhelm Roux's Entwicklungsmech. Org. 171, 259-268.

DAvid, C. N. (1983). Dissociating hydra tissue into single cells by the maceration technique. In "Hydra: Research Methods" (H. M. Lenhoff, ed.), pp. 153-156. Plenum, New York/London.

David, C. N., and CAMPBEL, R. D. (1972). Cell cycle kinetics and development of Hydra attenuata. I. Epithelial cells. J. Cell Sci 11, 557-568.

DONACHIE, W. D. (1968). Relationship between cell size and time of initiation of DNA replication. Nature (London) 219, 1077-1079.

Fantes, P. A., and NuRSE, P. (1977). Control of cell size at division in fission yeast by a growth modulated size control over nuclear division. Exp. Cell Res. 107, 377.

FUJISAWA, T., and DAvid, C. N. (1983). Nematocyte loss induced by regeneration and wound healing in Hydra. In press.

GAUTHIER, G. F. (1963). Cytological studies on the gastroderm of Hydra. J. Exp. Zool. 152, 13-39. 
Loomis, W. F. (1954). Environmental factors controlling growth in hydra. J. Exp. Zool 126, 223-234.

LoOMIS, W. F. and LENHOFF, H. M. (1956). Growth and sexual differentiation of hydra in mass culture. J. Exp. Zool 132, 555-574.

MARCuM, B. A., and CAMPBELL, R. D. (1978). Developmental roles of epithelial and interstitial cell lineages in hydra: analysis of chimeras. J. Cell Sci 32, 233-247.

Mrtchison, J. M. (1977). The timing of cell cycle events. In "Mitosis. Facts and Questions" (M. Little et al, eds.). Springer-Verlag, Heidelberg/New York.

OTTO, J. J., and CAMPBELL, R. D. (1977). Tissue economics of hydra: Regulation of cell cycle, animal size and development by controlled feeding rates. J. Cell Sci. 28, 117-132.

PrescotT, D. M. (1981). Analysis of the cell cycle of mammalian cells. Verh. Dtsch. Zool. Ges. 119-126.

RomeIs, B. (1968). "Mikroskopische Technik." Oldenbourg, Munich/ Vienna.

SCHROEDER, L. (1969). Population growth efficiences of laboratory $H y$ dra pseudoligactis Hyman populations. Ecology 50, 81-86.
Sriven, A. E. (1962). The effect of temperature and feeding on the intrinsic rate of increase of three species of hydra. Ecology 43(2), 325-328.

Sugryama, T., and Fujisawa, T. (1978). Genetic analysis of developmental mechanisms in hydra. V. Cell lineage and development of chimera hydra. J. Cell Sci. 32, 215-232.

Takano, J., Fujisawa, T., and SugiYama, T. (1980). Growth rate and cell cycle of $H y d r a$. In "Developmental and Cellular Biology of coelenterates" (P. Tardent and R. Tardent, eds.). Elsevier/North-Holland, Amsterdam/New York.

TAKANO, J., and SUGIYAMA, T. (1983). Genetic analysis of developmental mechanisms in hydra. VIII. Head-activation and head-inhibition potentials of a slow-budding strain (L4). In press.

TAKANO, J. (1983). Genetic analysis of developmental mechanisms in hydra. IX. Effect of food on development of a slow-budding strain (L4). In press.

Walters, M. N. J., and Papadimitriou, J. M. (1978). Phagocytosis: A review. Crit. Rev. Toxicol. 5, 377-405.

ZIHLER, J. (1972). Zur Gametogenese und Befruchtungsbiologie von Hydra. Wilhelm Roux's Arch. Entwicklungsmech. Org. 169, 239-267. 